\title{
Turn-Initial Discourse Markers in L2 Spanish Conversations: Insights from Conversation Analysis
}

\section{Marta García García ${ }^{1}$ (D)}

Received: 5 August 2019 / Accepted: 27 December 2019 / Published online: 22 January 2020

(c) The Author(s) 2020

\begin{abstract}
Turn beginnings are the place in conversation where the connection (or otherwise) between a prior and a next turn is displayed. This crucial interactional task is usually fulfilled by turn-initial particles, specifically those known as discourse markers. Although the use of discourse markers by second or foreign language speakers has actually been largely discussed in the previous literature on interlanguage pragmatics, studies that focus on turn-initial discourse markers and that are conducted from a conversation analytical perspective are still scarce. The aim of this paper is therefore twofold. On the one hand, it makes a case for the use of conversation analysis as a research methodology for the study of discourse markers in a second or foreign language. On the other hand, and as a practical elaboration, this paper investigates the use of the discourse markers " $y$ " and "sí" in the turn-initial position by foreign language speakers of Spanish. The results show that both discourse markers are part of an overall concern of signalling continuity and affiliation even in topic shifts and in non-aligned turns.
\end{abstract}

Keywords Discourse markers · Conversation analysis for SLA · L2 Spanish · Topic management $\cdot$ Continuity $\cdot$ Alignment

\section{Introduction}

Although initially seemingly straightforward, taking turns talking in multi-party conversations constitutes one of the most sophisticated actions that people accomplish when managing social relationships in their daily lives. Upon further reflection, successful participation in conversation is revealed as if not a "miracle" (Levinson $2013,103)$, then as at least collaborative work of the highest precision: participants talk (almost always) one at a time, speaker changes occur (mostly) in perfect timing,

Marta García García

marta.garcia@phil.uni-goettingen.de

1 Department of Romance Languages, University of Göttingen, Humboldtallee 19, 37073 Göttingen, Germany 
and individual contributions do not just follow one another independently but are (usually) perfectly interwoven.

Considering the amount of conversational work that speakers have to manage, the task of speaking with other people in a second or a foreign language (L2) ${ }^{1}$ should not be underestimated. Language learners with not yet fully developed linguistic resources are faced with the task of minutely timing their turns and adapting their contributions to the contingencies of interaction. This task implies listening to and making efforts to understand interlocutors and, at the same time, planning what is going to be said and when and how it will be said in such a way that fits (see Sect. 3) with the immediately previous talk. These "fine-grained techniques that are needed to successfully engage in L2 interaction" (Pekarek Doehler and Berger 2018, 555; emphasis in original), currently referred to as Interactional Competence (Hall et al. 2011), have usually been neglected in classic accounts (Hymes 1972; Canale and Swain 1980; Celce-Murcia 2007) of what it means to be communicatively competent. In the Common European Reference Framework (2001), the activity of speaking in interaction is in fact considered, but issues such as how to take a turn remain unspecified or at least not specified with the necessary degree of granularity.

Therefore, there is a strong need for more detailed descriptions of what it means to take a turn in an L2. The present paper accordingly addresses this dimension of Interactional Competence and focuses on the specific issue of establishing coherence with previous turns in turn beginnings. As will be shown later, competent (native) speakers usually draw on turn-initial particles, specifically, discourse markers, to display inter-turn relationships. Although the use of discourse markers (DMs) by L2 speakers has been largely discussed in the previous literature on interlanguage pragmatics in languages such as English (e.g., Buysse 2012; Diskin 2017; House 2013; Polat 2011) and Spanish (e.g., Campillos Llanos and González Gómez 2014; FloresFerrán and Lovejoy 2015), studies of these "little words that matter" (Bolden 2006) in an L2 conducted from a conversation analytic perspective are still scarce (however, see Wong 2000; Kim 2009 and Pekarek Doehler 2018 for some exceptions).

The structure of this paper is as follows. As one of the aims is to make a case for the use of Conversation Analysis (CA) as a research methodology for the study of DMs in an L2, this study begins with a brief discussion of the contents of CA and the conversation analytical perspective and the contributions of CA to and its potential for the study of DMs in L2 use. An overview of the role of DMs in turn beginnings follows, and as a practical elaboration, this paper presents an analysis of two very common DMs ("y" and "sí") in a corpus of L2 Spanish conversations.

\footnotetext{
${ }^{1}$ In this paper, L2 is used as an abbreviation for both a second and a foreign language. In addition, the terms L2 speakers and L2 learners or language learners are used as synonyms.
} 


\section{The CA Perspective on (L2) Interaction}

CA has its roots in Ethnomethodology, a branch of sociology founded by Harold Garfinkel. Although most sociological approaches are interested in macrosocial constructs (such as power, gender or family) and, more importantly, conceive of them as already existing structures with rules that members must strictly follow, the ethnomethodological understanding of social reality is that of "an ongoing accomplishment" (Garfinkel 1967, 1). This perspective is a radical departure from the aforementioned perspective, as social order is thus seen as a collaborative achievement: social order is not imposed on members of society but is instead "created" by them through their participation in social practices, which materialize through talk-in-interaction.

The workings of social relations from governments and educational systems to friendships and intimate relationship are co-constructed through interaction or more precisely talk-and-bodies-in-interaction. It is, in part, through social interaction that schooling is done, morality is made visible, and financial trades are accomplished. And it is through social interaction that members of society claim and negotiate their identities [...] (e.g., democrat, police officer, gay) and where participants recognize when someone is behaving 'abnormally'-whether this 'behavior' can be clinically categorized (e.g., Tourette syndrome, aphasia, non-native speaker) or not (e.g., weird, sociopath) (Mortensen and Wagner 2012, 1063).

Thus, according to the conviction that interaction lies at the heart of society, Sacks et al. (1974) developed a methodology called Conversation Analysis for the study of ordinary interactions, with the aim of discovering the methods of conversation, i.e., the systematic ways in which participants organize their talk and make sense of the talk of other people. These methods are ultimately the key to understanding how interaction and, thus, society work.

These sociological roots explain why the main interest of CA lies not in language, or at least not in its formal properties, but in language as action. Although this focus of CA is strongly reminiscent of the "how to do things with words" of Austin's speech acts theory, there are fundamental differences between classic Pragmatics and CA. First, CA understands "doing things" in a much broader sense than as speech acts for which there is a vernacular term (i.e., greeting, offering, requesting, complaining) and emphasizes other types of action, such as news announcements, pre-closings, and knowledge claims (Schegloff 2007). This understanding is indeed possible because, second, CA is conducted strictly inductively through an "unmotivated looking" (Psathas 1990, 3) in search of noticeable phenomena in the data; third, nothing is rejected a priori as meaningless or insignificant because it is argued that the participants orient to every small detail of an interaction (Wooffitt 2005, 79). The contribution of CA thus relies on its power to reveal with 'microscopic' precision and, simultaneously, look in an unmotivated manner for the "delicacies of design and management that resist the assaults of clumsier instruments" (Richards 2005, 3). Finally, CA's approach to 
language as social action has two fundamental consequences for analytical work. First, the contributions to talk (turns) are not considered to be individual but joint accomplishments. Participants never speak alone but design and re-design their utterances according the specific reactions that they want to trigger (a question has to be constructed as a question if a participant wants an answer) and according the signals (i.e., nods, silences, and puzzled looks) that come from the coparticipants. Speaker and listener are thus problematic categories in CA because listeners also talk (Gardner 2001) or, more precisely, influence talk. Furthermore, the design of a turn is always because of a prior turn and establishes requirements for the next turn; therefore, a contribution can be studied only in the sequential environment in which it is produced.

Based on these distinctive analytical characteristics, CA has great analytical power for the study of L2 learning and use and extends the research scope of Second Language Acquisition studies. Instead of focusing on questions about grammar, pronunciation and vocabulary and on how well the forms, meanings and sounds are acquired by individuals (usually) in laboratory settings, CA focuses on how L2 learners become more competent participants in different natural contexts. This approach implies that the attention is not directed at the target-language-like or deviant uses of a linguistic form, such as past tenses in narratives, but on the interactive resources that participants deploy, for example, to indicate that a storytelling is about to start or to conclude, that a story is completely unrelated or extremely related to what has been previously said, or that participants are ready to listen and paying attention. This emphasis on language as action and in action characterizes the analytical aspect of CA and allows new insights into how L2 learners manage to effectively cope with the contingencies of interaction with other people.

One of these contingencies, initiating a turn, and its meaning in terms of interactional work, will be addressed in the next section.

\section{Discourse Markers in Turn Beginnings}

As previously stated, people do not make isolated contributions in talk-in-interaction. Thus, a central notion in CA is that of nextness: each unit of talk builds on the prior talk, and participants stay under the "normative pressure" (Heritage 2013, 333) to understand a turn as tied to what has been said immediately before. At the same time, each turn establishes a (limited) range of options for the next possible action. This "Janus-faced property" (Heritage and Sorjonen 2018, 13) becomes highly visible and relevant at turn beginnings: the "turn-initial position is also the first moment in the turn that reveals their [next speakers'] analysis of the prior speaker's turn, projecting the action underway" (Kim and Kuroshima 2013, 268).

Both the tasks of reaction and projection can be displayed in an "unmarked" manner (Heritage 2013, 333), which occurs when the current speaker has just signalled the uptake of the prior turn and projects "a sequence of turns within some expected set of parameters" (ibid.). However, the next speaker may also feel the necessity to explicitly mark the disconnection between the prior and emerging turn, for example, in contexts where the range of possibilities for a next action is very narrow (as in 
answers to questions), or on the contrary, the next speaker may initiate a turn that indicates a not immediately evident relationship with previous talk. In addition, just as turn beginnings are a privileged place to show inter-turn connections, languages have developed specific devices to fulfil this interactional task. I refer here to terms such as "well", "but", "yeah", "you know" and "anyway" in English or in Spanish, "bueno", "pues”, "vale”, "sí”, "por cierto", “y”, or "o sea”, which are usually called discourse markers (DMs) but are also known as discourse particles, pragmatic markers or conversation management devices. This "considerable terminological diversity" (Heritage and Sorjonen 2018, 2) is because of the variety of perspectives from which DMs have been intensively studied since the late $1980 \mathrm{~s}$ and due to this issue, a standard definition or even a common agreement about what counts as a DM is lacking. Similar to Waring (2003, 416), I avoid entering conceptual and terminological discussions and

use 'discourse marker' loosely as a cover term for those words or expressions that rise above their semantic/referential meanings to take on complex interactional duties or so-called 'discourse meanings'.

Consistent with the methodological principles described in Sect. 2, DMs are, from a conversation analytic approach, not studied as lexical units in terms of their inferential or logical meanings but as "harbingers of stance and action in interaction" (Heritage and Sorjonen 2018, 5). Moreover, CA is interested in revealing the intricacies in the use and function of DMs derived from details such as their position in turns and the position of a turn in a sequence.

The aim of this paper is therefore to provide a conversation analytic description of the deployment of two DMs ("y" and "sî") in L2 Spanish conversations. Consistent with the contributions in Heritage and Sorjonen (2018), this paper adopts a semasiological approach and starts with linguistic forms to examine actions. The rationale for the focus on these two DMs lies not only in their frequency in the corpus (which will be presented in the next section) but also in their role-as will be shown-in conveying continuity and thus minimizing disjunction. This issue is central because, as Heritage states $(2013,334)$, "in building these sequential connections participants, are [...] also building social relationships as well”. How L2 learners cope with the tasks of connecting turns and managing social issues thus becomes a highly relevant question that the present study aims to answer.

\section{Data}

The data for this study originate from a corpus (García García 2014) of 10 audiorecorded multi-party conversations between adult learners of Spanish, which amount to $276 \mathrm{~min}$ of transcribed talk. ${ }^{2}$ In each conversation, three students of

\footnotetext{
${ }^{2}$ Regarding the size of the corpus, it should be noted that CA does not aim at collecting representative samples of data, "simply because nobody knows what 'representativeness in interaction' means" (Wagner and Garnder 2004, 4).
} 
German Universities who were attending the same Spanish course together and who were therefore of approximately the same proficiency level participated, and they ranged from $\mathrm{A} 2$ + to $\mathrm{B} 2$ according to the Common European Reference Framework. Twenty-three of the 30 participants had German as their only first language, one of them had Russian as a first language and the other 6 grew up as bilinguals.

The conversations were not elicited in a pedagogical setting, strictly speaking, as the recordings were made outside of lesson hours and were unrelated to the Spanish course itself. The participants were asked to talk "for approximately 30 min"; thus, they were not fulfilling a lesson task. Accordingly, the recordings were not instances of classroom discourse. Nevertheless, the researcher was also the language teacher of the participants, the location was the same university room in which the course usually took place, and the students had been given a text that they could use to discuss. ${ }^{3}$ That is, it is not possible to treat the data as spontaneous conversations. Interestingly, in each triad, the participants interpreted this ambiguous setting differently. As discussed in detail in García García (2015), in some conversations, participants are getting acquainted, in other conversations, they approach the activity as discussing a text, and other conversations exhibit characteristics of both genres at different time points.

For the analysis, all the occurrences of "y"- and "sí"- prefaced turns in the corpus were collected. The results are presented by following a very succinct-due to space limitations - review of the previous research on each DM.

\section{"Y"-Prefaced Turns}

Studies of " $y$ " that consider the sequential context in interactional environments are scarce. Pons Bordería (2000) classifies "y" as a DM with the regulative (i.e., demarcative) value of signposting a thematic continuation or progression through different speakers and turns. Noting the same function of indexing continuity, Cestero Mancera (2000a, 173) mentions the use of " $y$ " in the turn-initial position as a topicshift device that instead of emphasizing the topic change, primarily hides it.

In this section, I examine some examples of " $y$ "-prefaced turns in the sequenceinitial position, that is, the turns that launch a new course of action, such as questions, commentaries or assessments. The analysis starts with the use of " $y$ " in the turn-initial position that prefaces topic initiations and topic shifts and then moves to cases of "y"-prefaced topic completions after silences.

\section{"Y"-Prefaced Topic Proffers}

Topic initiations are, following Wong and Waring (2010, 105), turns in which a new, non-related topic is introduced either "(1) during conversation openings; (2) after closings have been initiated; (3) after the shutdown of a prior topic, (4) following

3 The students could discuss it but did not have to, which was explicitly communicated to them. 
a series of silences". A possible way to generate topical talk in such environments is producing a topic proffer (Schegloff 2007, 169ff), that is, an invitation to talk that is usually in the form of a question for which the recipient is the "authoritative speaker" (p. 170). Excerpt (1) ${ }^{4}$ illustrates a canonical example of a topic proffer. The participants are discussing their university degrees, which is a very common topic in the corpus, and here, $\mathrm{CF}$ is explaining what her original motivation was for choosing to pursue an MA in African Studies.

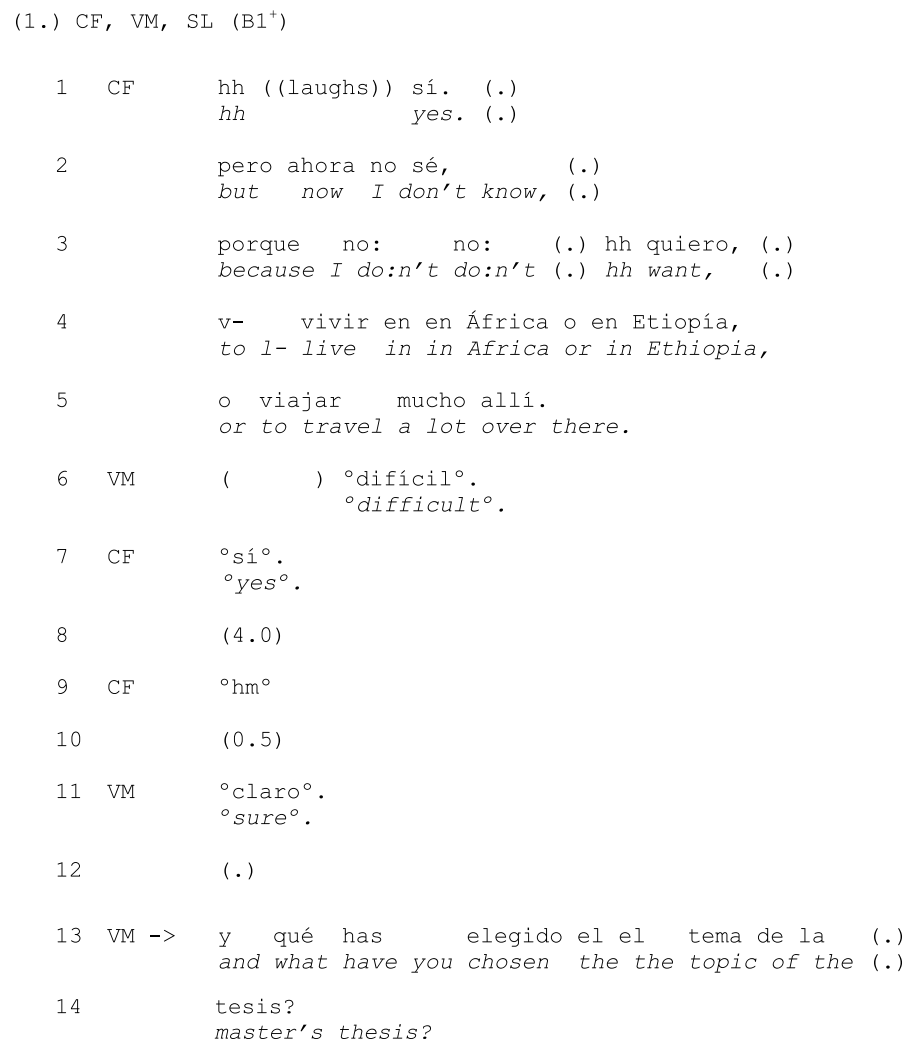

CF recognizes that she is now not sure about her willingness to work in the field of African Studies because she does not want to live in or frequently travel to Africa (1. 1-5). Then, VM affiliates with her and values the perspective of working in this field as "difficult" (1. 6), with which CF agrees (1. 7). A silence, a continuer (hm) and another agreement ("claro") follow; this series of content-empty turns is typical for

\footnotetext{
${ }^{4}$ Due to space reasons, it is not possible here to provide a three-line transcription (original talk, morpheme-by-morpheme English gloss and idiomatic translation) of the excerpts. Thus, the second English line is a balance between fidelity to the original talk (with non-target forms) and legibility: an asterisk (*) stands for the non-target-like forms in the original, and what the wrong form consists of is glossed in small capital letters.
} 
topic closings and is an indicator that the topic has become exhausted. VM's question in line 13 is thus a strategy to reactivate topical talk and avoid an even longer lapse. He asks about the theme of CF's Master's thesis (a question for which only $\mathrm{CF}$ has the relevant answer), which is successful, as it indeed triggers an extended turn by CF. The "y" at the beginning of VM's question establishes a link between the question and the previous topic (which had been already closed) and successfully undermines the "default expectation" (Heritage 2013, 334) that after a topic closing, a new topic begins.

These "y"-prefaced topic proffers are quite frequent in the data. ${ }^{5}$ A special type of topic proffer is that which I have elsewhere named a rotation series (García García 2014), which are rounds in which each speaker reports on the same type of experience (for example, living abroad) one at a time or responds to the same personal question (for example, "where do you come from?"). Rotation series are a very common phenomenon in the present dataset, probably due to the hybrid elicitation conditions. Understood as social talk, the participants use the conversation to get acquainted and show interest in everyone; understood as classroom discourse, the participants approach the talk as a task for which everybody has to contribute. Excerpt (2) provides a good example of these rotation series. Prior to line 1, a sequence about homesickness was closed. EE's question in line 1 connects to a prior similar question ("in 10 years, do you want to live in Germany?") previously stated by MS to AS.

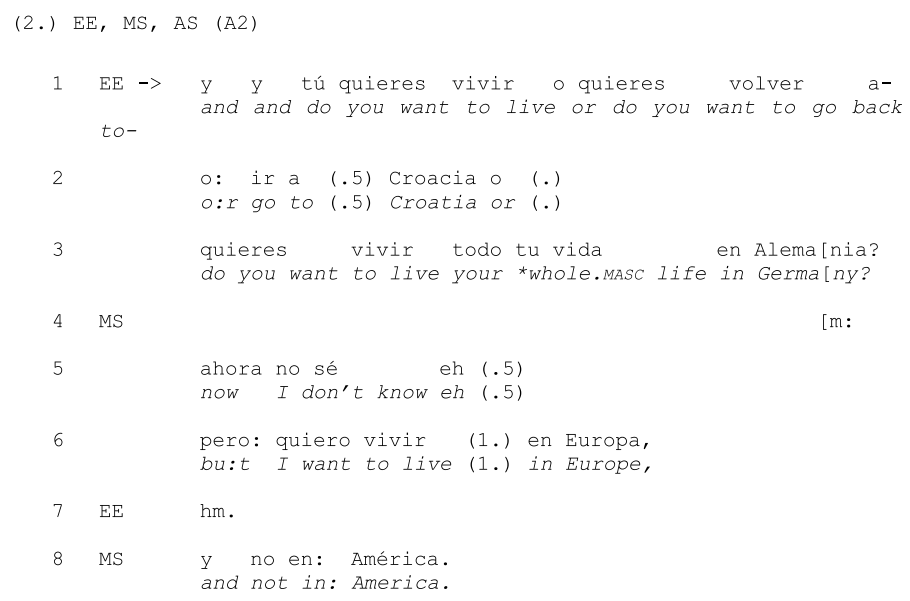

The DM " $y$ " functions here as a device to display the connection between the current question and a previous (not immediately preceding) question. In this sense, the use of the DM is very similar to the use observed by Heritage and Sorjonen

\footnotetext{
5 This so-called "informal quantification" through adjectives such as common, frequent or typical rather than relying on percentages is a conscious methodological decision in CA. For a detailed discussion on the issue of quantification in CA, see Schegloff (1993).
} 
(1994) for the case of "and"-prefaced questions in English in the context of medical visits: "and" treats each question as being linked to another and "being agendabased parts of some larger course of action" (p. 24). Here, and in a very similar way, the participants invoke a relationship between all the questions of the series and treat them as pertaining to a list or an underlying agenda for the activity.

This property of " $y$ " also applies to topic proffers that are not other-attentive, as opposed to the previous examples. In Excerpt (3), CM, AW and IL are discussing living costs in different European countries, and the discussion ends with the special case of Firenze, which is in a southern city but is very expensive with a high standard of living (1. 1-8).

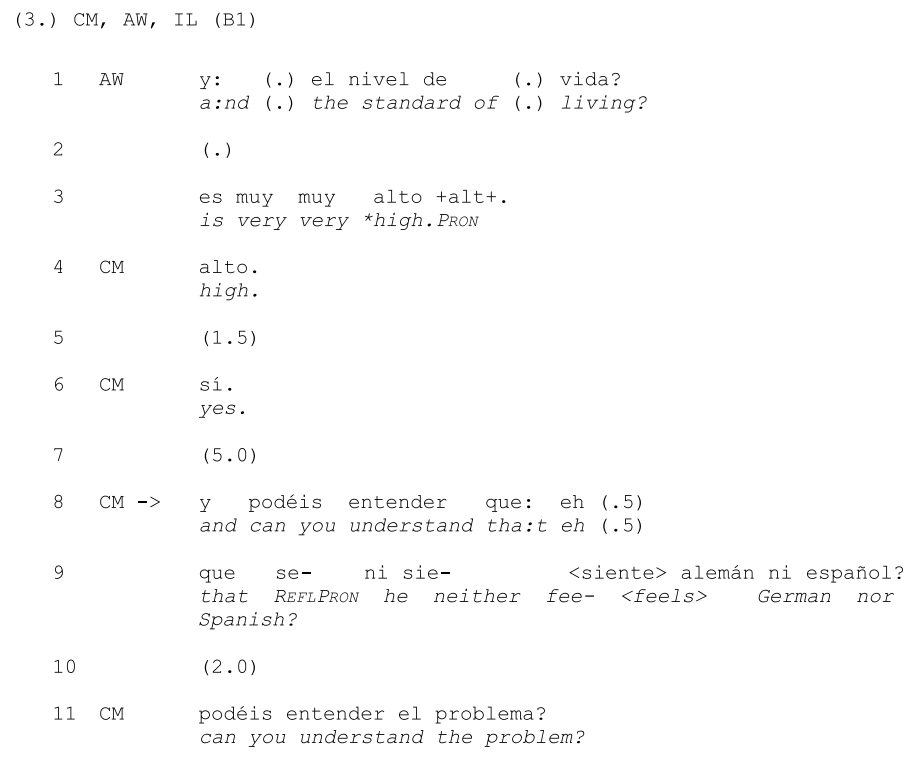

AW's last turn ends in line 3 with a mispronunciation of the word "alto" (high), which is other-corrected by CM in the next turn. As no speaker self-selects, the conversation comes to a relatively long pause (1. 5), CM produces a "sí" as an agreement token, and again, no participant takes the turn. After this closing sequence, CM's new turn in line 8 initiates a completely new topic in the form of a "y"-prefaced question about the text that they all had read in advance. Note that in this new turn, CM's question appears to be related to previous topics ${ }^{6}$ and appears not to be completely unrelated. Showing a rationale for the initiated topics thus seems to be of high relevance for the participants in the corpus. ${ }^{7}$

When not "y"-prefaced, the questions have a very different effect, as illustrated in the following two excerpts.

\footnotetext{
${ }^{6}$ A very significant part of this conversation actually revolves around the protagonist of the proposed text.

7 To the best of my knowledge, there are not equivalent studies of topic proffers in L1 Spanish, but as a term of comparison, none of the English topic proffers examined in Schegloff (2007) is introduced by a turn-initial element.
} 
(4.) $\mathrm{CF}, \mathrm{VM}, \mathrm{SL}(\mathrm{B} 1+)$

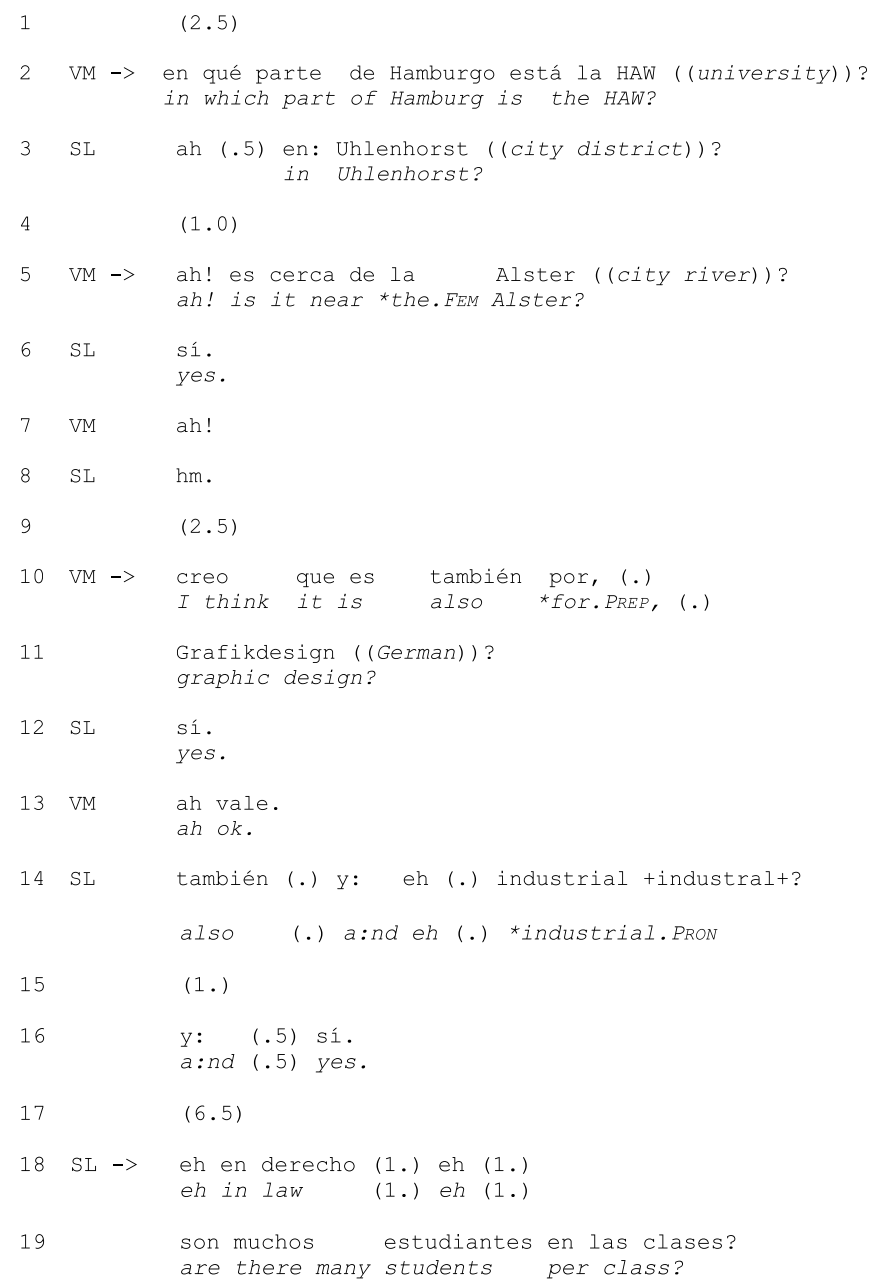




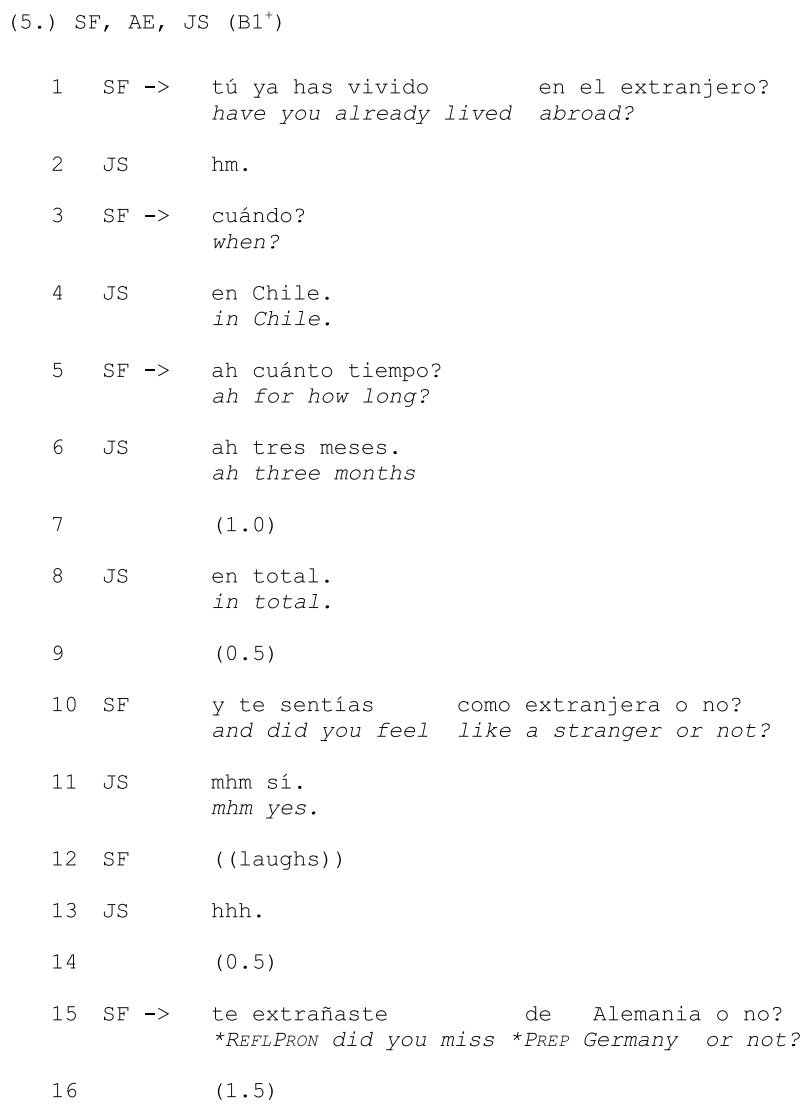

VM's and SL's questions in Excerpt (4) seem like loose, random elements in the flow of the conversation, while the entire fragment in Excerpt (5) with only one " $y$ "prefaced question produces the effect of an interrogation by SF of JS, which is also displayed in the short answers of JS. She does not interpret the questions as an invitation to talk (the questions are indeed not designed as such invitations) but rather as an information exchange. In certain conversational environments, initiating a question with or without " $y$ " may have consequences at both the discourse and interpersonal levels.

\section{"Y"-Prefaced Topic Shifts}

The second context in which a "y"-prefaced turn appears to initiate a new sequence is that of topic shifts. Topic shifts, unlike topic initiations, occur within a current topic and refer to practices either of "(1) shifting emphasis within a topic or (2) moving towards a [fully] new topic" (Wong and Waring 2010, 115). The main job of " $y$ " in this context is opposite to the main job of typical disjunctive markers such 
as "por cierto" or "a propósito" (by the way, talking of), as it signals (a real or not real) connection to previous talk and thus hedges the topical shift (Cestero Mancera 2000a). In the corpus, topic shifts occur with both questions to the other participants (Excerpt 6) and self-oriented announcements (Excerpt 7) ${ }^{8}$

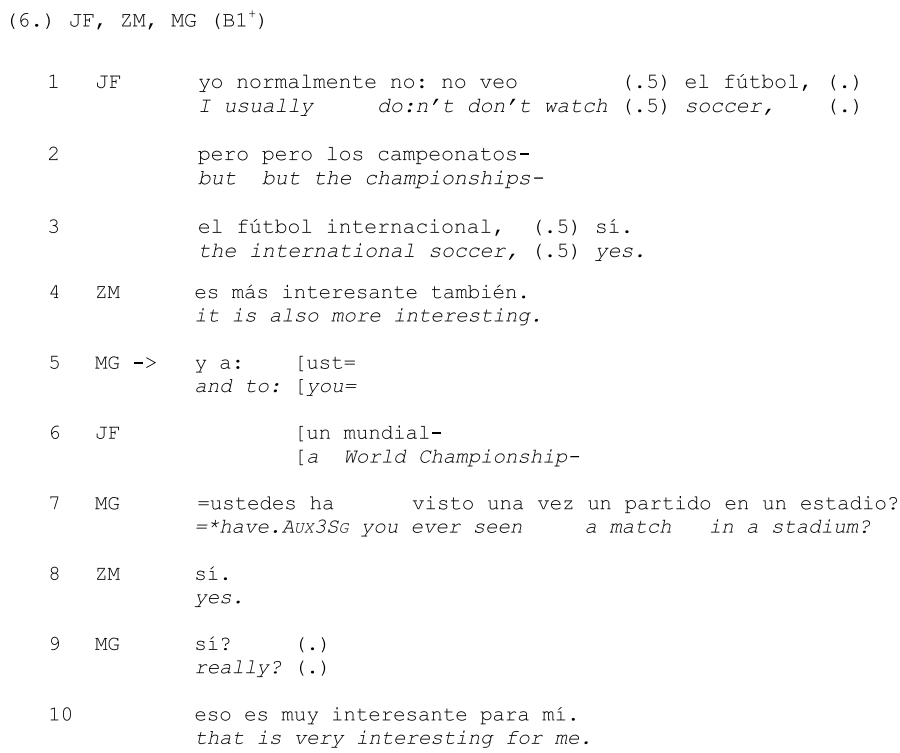

${ }^{8}$ Both cases are instances of shifting emphasis, i.e., they involve "a move from one aspect of a topic to another" (Maynard 1980, 271). 


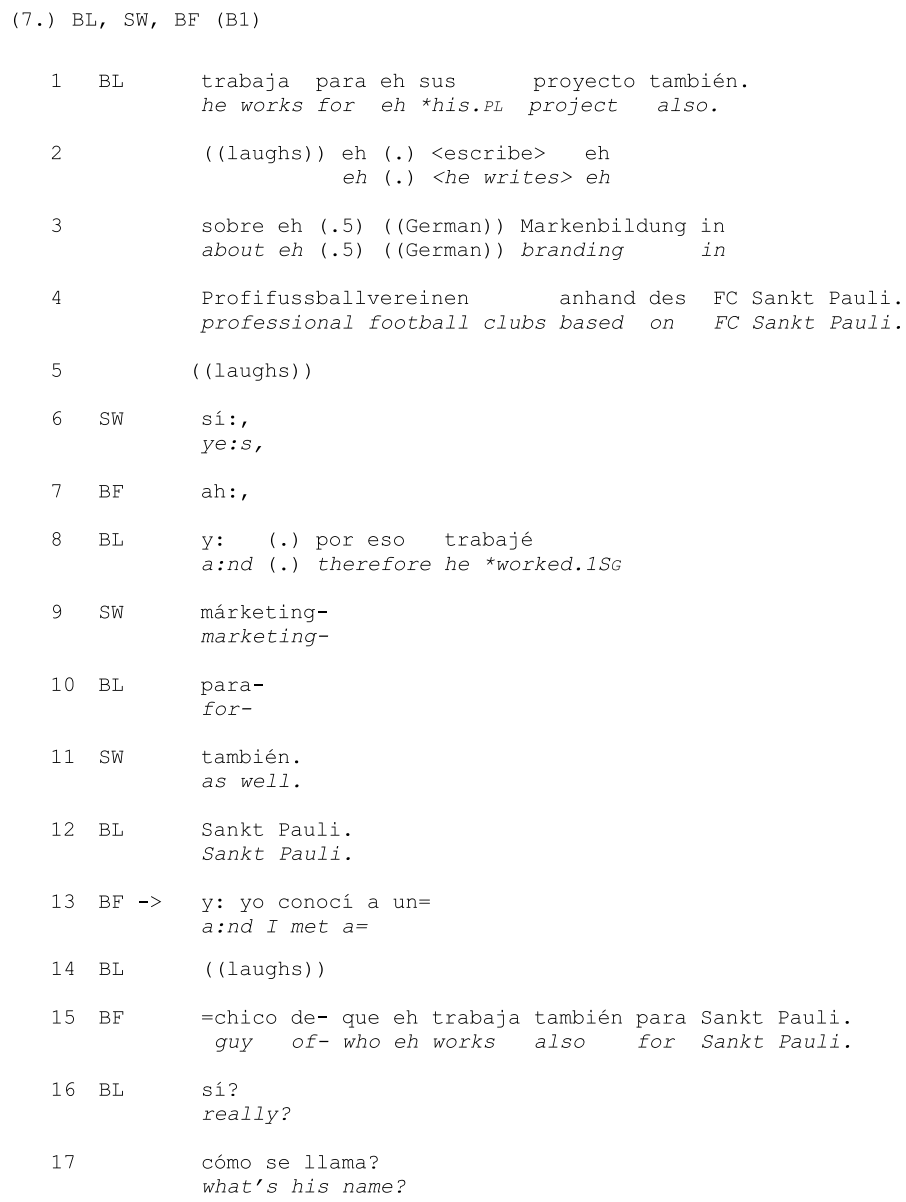

In Excerpt (6), the participants are discussing the performance of the different European football teams at the 2004 European Championship. In lines 1-3, JF produces what seems to be a justification for her interest in this and other international football competitions. After ZM's affiliation (es más interesante también), MG's question in lines 5-7 shifts the topic from "championships" to "live matches". In Excerpt (7), BL is talking about her boyfriend, who is writing his Master's thesis about marketing in professional football. The name of the football club in Hamburg (FC St. Pauli) serves as a pivot for BF's announcement in line 13, which steers the conversation towards a mutual friend. Both cases are instances of stepwise topic shifts and are thus the "best way to move from topic to topic" (Sacks 1992, 566). MG and BF's choice to use "y" as the turn-initial DM reveals the participants' constant concern for indexing continuity between stretches of talk. 


\section{"Y"-Prefaced Topic Continuations}

This concern for indexing continuity is even more obvious in contexts such as the first turn after a closing, where the normal expectation is a turn that initiates a new topical thread. If this is not the case and the speaker who self-selects after the closing actually continues with the previous, closed thematic activity, s/he is under the interactional pressure of presenting the relationship of her/his turn with the previous line of talk in a way that is recognizable to the co-participants. This expectation applies to cases when the speaker extends her/his own previous turn either after a silence (Excerpt 8) or after an inserted sequence (Schegloff 2007), as in Excerpt (9).

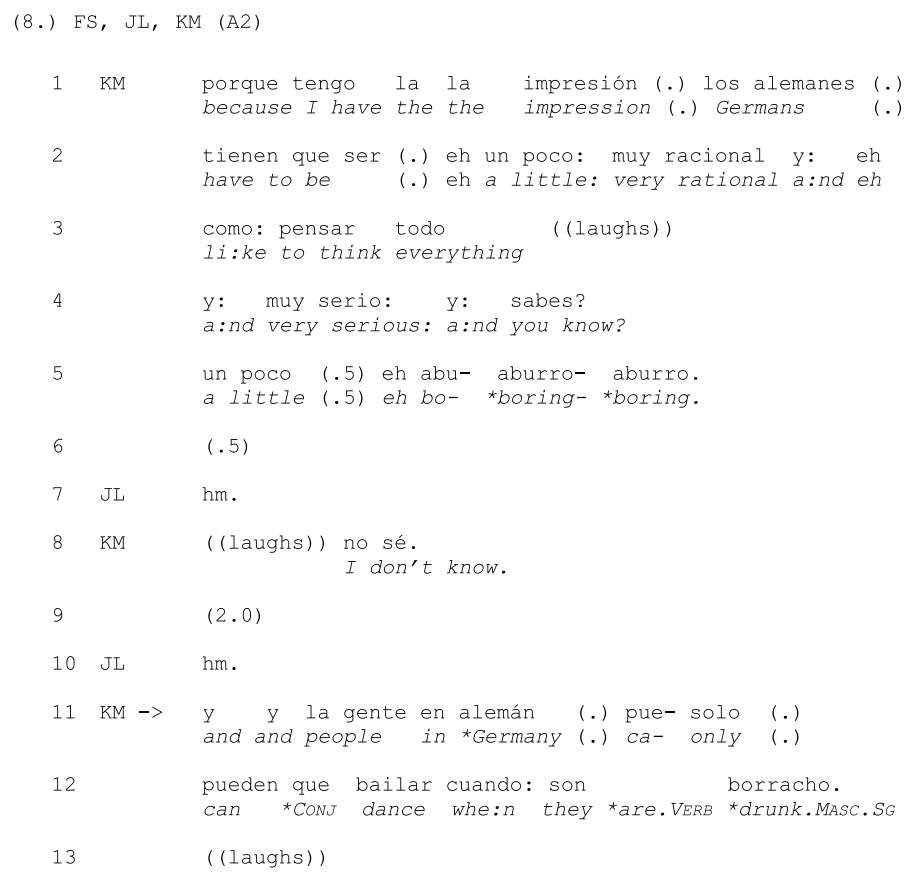


(9.) $\mathrm{PE}, \mathrm{DM}, \mathrm{MR}$ (B2)

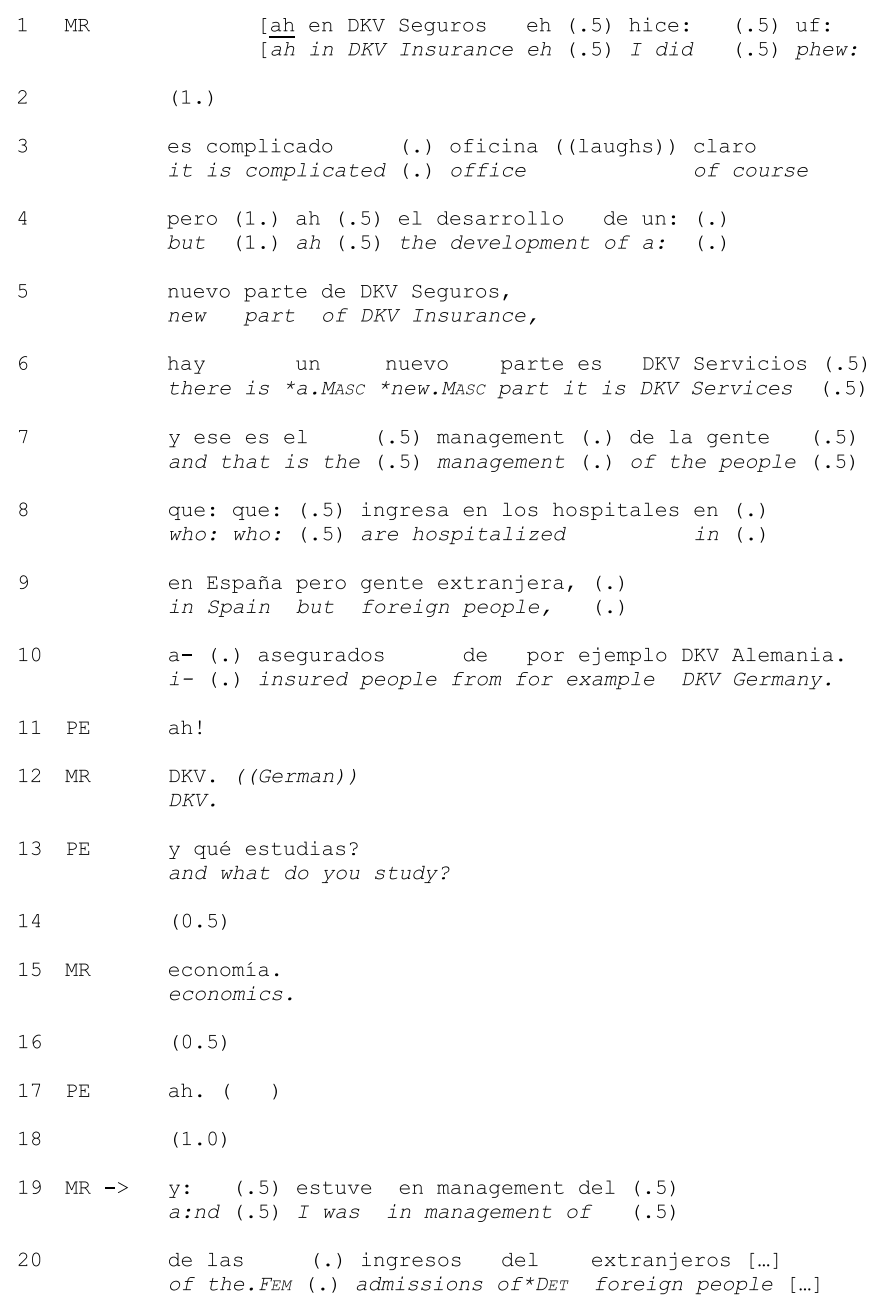

In Excerpt (8), $\mathrm{KM}$ is discussing her study abroad experience in Spain and what is considered "typical for Germans" in Spain (1. 1-5). A series of content-empty turns follows (1. 6-10), and finally, KM self-selects and adds another stereotype about Germans to the previous list. The turn-initial "y" marks the relationship with previous talk and thus prevents the interpretation of this turn as KM's own opinion. The topic continuation in Excerpt (9) occurs in a slightly different context. Here, it is not a silence or a topic closure that comes in between lines 12 and 19 but an inserted sequence in the form of a question-answer sequence. The " $y$ "-prefaced turn resumes "a course of action" and treats prior talk as an interruption of the main activity, as Heritage and Sorjonen $(1994,15)$ observed for "and"-prefaced questions in English. 
As illustrated in the cases analysed in this section, a turn-initial " $y$ " in the context of topic management is deployed to invoke a non-evident relationship or continuity between the new and previous segments of the conversation. This occurs when the related topic has been either already closed or somehow interrupted through an inserted question-response sequence or when the new topic is meant to belong to an underlying agenda for the conversation. Thus, "y", in its function as a DM in turn beginnings, is a "backward looking" (Heritage and Sorjonen 2018, 15) device that contributes to sustaining coherence over turns, which seemed to be an important issue for the participants. In this sense, "y" seems to play a significant role not only at the coherence level (indexing continuity) but also at the affective level (making why that now explicit for the co-participants).

\section{"Sí"-prefaced turns}

The polarity adverb "sí" is one of the most frequent but also one of the least studied Spanish words (Dumitrescu 2008, 233). According to Martín Zorraquino and Portolés Lázaro (1999, 4191ff), "sî" (as well as the particle "ya") belongs to a specific class of meta-discursive conversational markers whose main function is simply to indicate message recipiency. However, due to its positive polarity, "sí" can also signal a cooperative stance towards the main speaker in the form of alignment or agreement tokens during, for example, a storytelling (Cestero Mancera 2000b). A second feature of "sî" is that it is more likely than "ya" or "mm" to appear followed by further talk in the same turn and thus to initiate a change in speakership (Martín Zorraquino and Portolés Lázaro 1999) or even a change in topic in an other-attentive manner, as Jefferson (1993) observed for the English token "yeah". In what follows, I consider only these instances of "sî" + further talk in the main speaker turns and not in the cases of backchanneling. This section begins with the turn-initial "sí" in topic shifts and then moves to cases of "sí"-prefaced non-aligned turns.

\section{"Sí"-Prefaced Topic Shifts and Topic Initiations}

The most frequent function of "sí" in the current dataset is equivalent to the aforementioned function observed by Jefferson (1993) for English "yeah" and is referred to as "exhibiting attention while shifting". The deployment of "sí" allows a topic movement from general to particular issues (Maynard 1980) or from speaker A to speaker B. Excerpts 10-11 illustrate how this type of "sî" is used. 


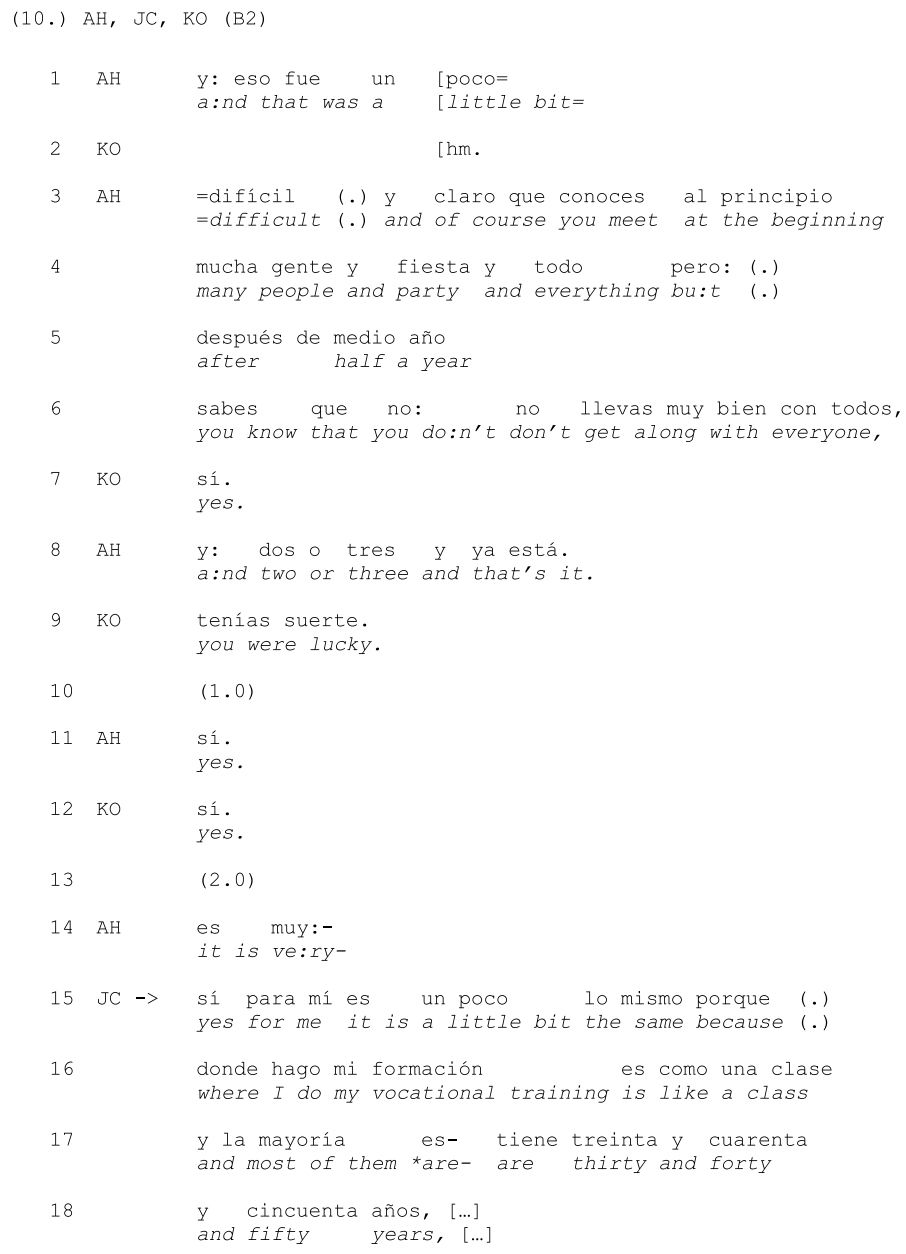

In Excerpt (10), JC uses the turn-initial DM "sí" to signal an affiliative stance (agreement) with the previous talk immediately before initiating a personal account (having problems making friends in a new place). The deployment of "sí" is highly relevant here because AH's prior turns are an instance of troubles talk (Jefferson 1984); therefore, in this context, a shift in topic towards a self-oriented topic could be viewed as inappropriate or misplaced. This is precisely what the "sî" and its implicit agreement attempts to minimize, and there is no better turn position for doing this than at the very beginning.

The case of Excerpt (11) is also similar. Prior to this segment, CF, SL and VM had been discussing the difficulties of living in Spain when one does not speak Spanish. In lines 1-3, CF expresses her opinion that Spaniards usually speak very quickly, which is a statement that VM and SL agree with (1. 4-7). 


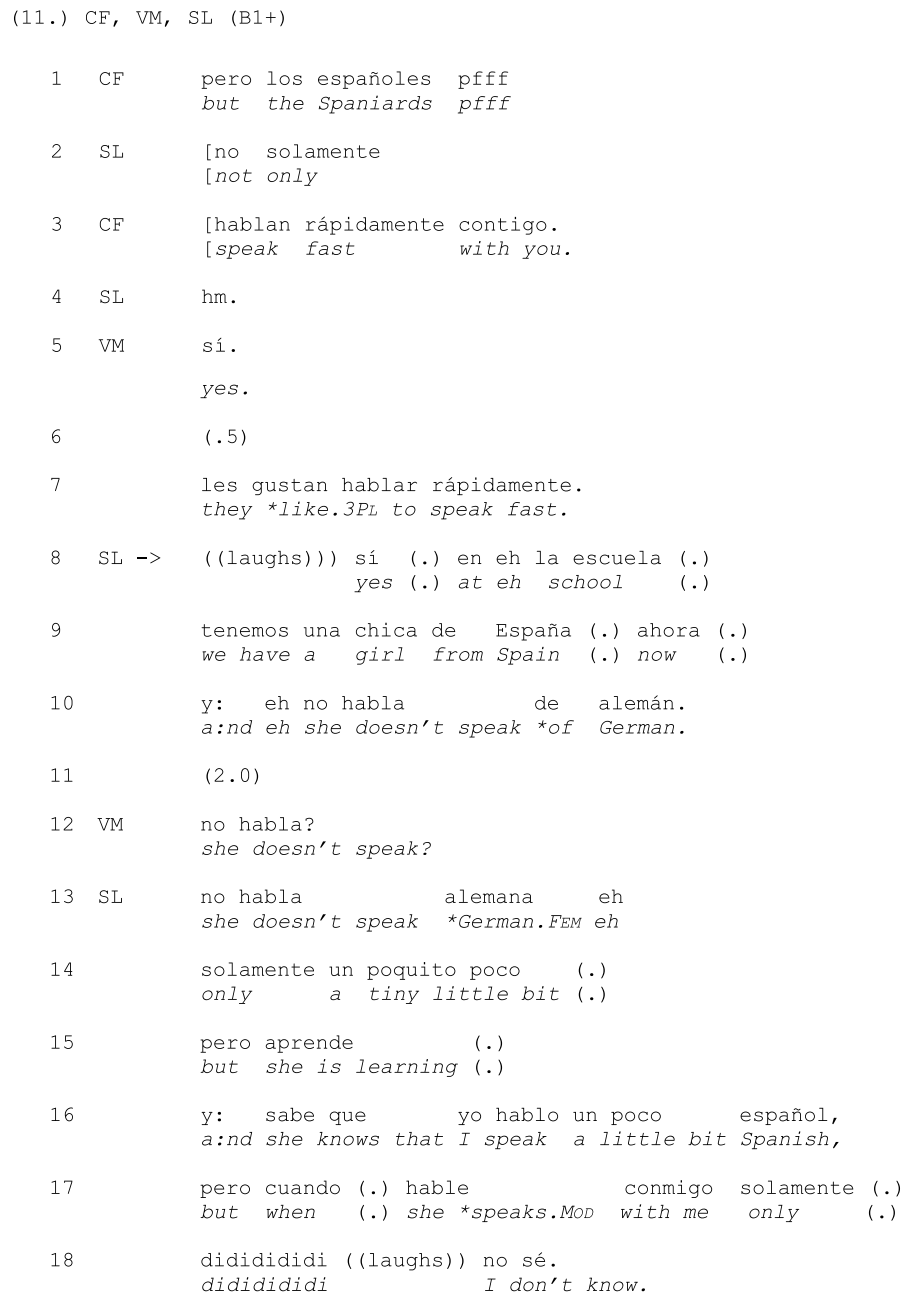

After her affiliative laughing, SL produces a new turn (1. 8), which shifts from general (Spaniards speak very quickly) to particular (a concrete example in the form of a personal anecdote) issues.

Another interesting case can be found in (12), which begins with IL's turn about the high numbers of German pensioners who live at the Costa Brava. IL continues reporting (1. 2-8) that the German government is establishing more 
strict conditions to receive one's pension when living abroad. This topic closes (1. 7-9), and after a short repair sequence in which CM, who has looked up the German word Rente in the dictionary, offers the Spanish word, nobody self-selects, and the conversation comes to a short lapse (1.15). Then, in line 16, IL produces a "sí"-prefaced turn in which she launches a new topical line about living costs in other countries (the same topical line of Excerpt 3 before).

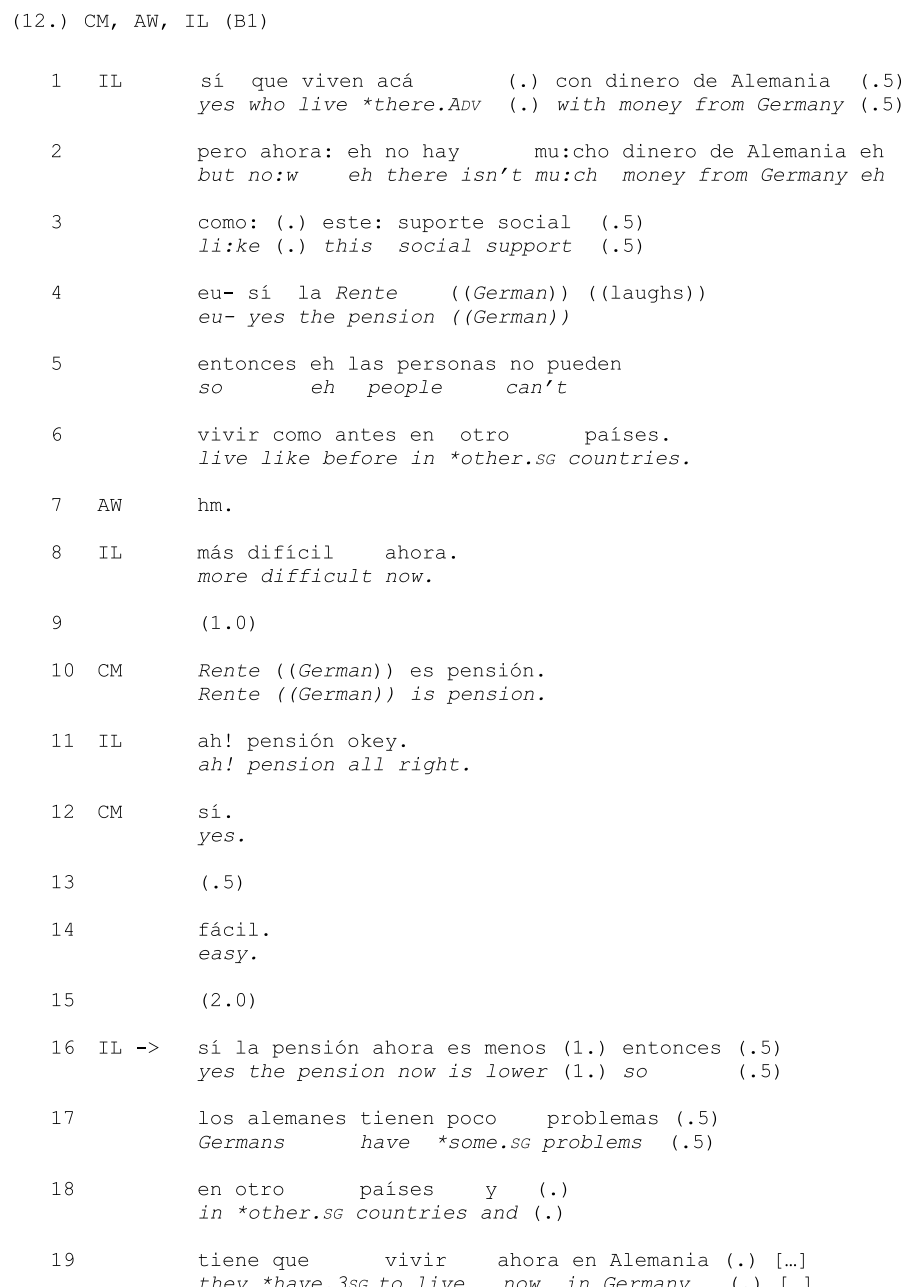


After the two-second lapse (1. 15), IL faces the interactional task of re-establishing topical talk. Without any turn-initial particle, IL's turn in line 16 would appear as "simply injected into the talk" (House 2002, 251). "Sí" is thus deployed here to establish a link to IL's own prior turn in lines 1-6, similar to the function of " $y$ " before topic continuations.

These excerpts illustrate a type of division of labour between "y"- and "sí"-prefaced turns. Although the "y"-prefaced turn is more neutral and objective and emphasizes marking continuity, the "sî"-prefaced turn is more other-attentive, proves "an account for taking the turn" (Fischer 2000, 126) and therefore seems to be more appropriate for self-oriented shifts following troubles-telling or an opinion, that is, in contexts that set preferences or expectations for alignment and agreement.

\section{"Sí"-prefaced non-aligned turns}

A special use of the turn-initial "sí" in first position turns found in the corpus is that of prefacing non-aligned turns, that is, the turns that do not match the expectations or formal preferences set by a prior turn. ${ }^{9}$

Consider Excerpt (13), which is taken from the very beginning of the conversation. KM begins with a personal statement (1. 1-2) related to the topic of the text, followed by her difficulties in understanding the feelings of the protagonist (1.3-9).

\footnotetext{
${ }^{9}$ For a review on alignment, see Steensig (2012).
} 
(13.) FS, IL, KM (A2)

1 KM vale ehm conozco mucha gente que: que: que son de: ok ehm I know many people who: who: who are from: una: país dist- de un país distinto; *a:.FEM country dif- from a different country; pero: ehm bu:t ehm

(1. 4)

senso? Gefühl ((German))?

*feeling? Gefühl? ((German))

7 JL sentido.

sense.

8 FS sentido.

sense.

9 KM sentido (1.) que: que el hombre habla de- habla sobre. sense (1.) tha:t that the man talks *of-talks about.

$10 \quad(1.0)$

11 JL $->$.h sí yo no <conozco> a mucha gente

.h yes I don't <know> many people

que viene de otros países

( (laughs))

who come from different countries

$13 \mathrm{KM} \quad(($ laughs $))$

14 JL de- eh de que viven en dos países más o menos .h of-eh of who live in two countries more or less.h

15 pero ehm y en la escuela,

but ehm and at school,

16 también hablamos mucho sobre: las problemas

we talked also a lot about *the. FEM problems

17 los problemas que tienen estas personas,

the problems that these people have,

18 .h que no: eh no dependen (.) a un país, (.) .h who don't eh don't depend (.) *PREP a country, (.)

19 que dependen dos países y que no saben (.) who depend two countries and who don't know (.)

$20 \quad$ dónde.

[where.

21 FS [( (clears throat $))$

(1.)

23 FS $\rightarrow$ sí eh en en la escuela: ha conocido eh una chica: yes eh at at school I * AUX. 3sG met eh a gi:rl

24 eh que eh que ha eh nació +'naөio+ en Rusia:? eh who eh who AUX eh was born in Russia:? y eh creo que es la: and eh I think that it is the:.FEM 
It is difficult to interpret JL's "sí" in line 11 as an alignment or agreement device: JL's turn is clearly misaligned to KM's prior turn because first, it is in overt opposition to KM's first turn component (KM says that she knows many people from other countries, and JL affirms that she does not) and second, it does not provide any response to KM's claim of non-understanding (no puedo entender) in lines 5-9. The same occurs with FS's turn in line 23, which also is a "sí"-prefaced turn following not an opinion but a fact (JL's second turn component: en la escuela hablamos mucho sobre los problemas). Thus, the turn-initial "sí" in lines 11 and 23 are not used to index any agreement with prior turns and do not function as a connecting device to the previous turns of JL or FS (as in Excerpt 12 in the case). Rather, both the turn-initial "sí" in lines 11 and 23 seem to be deployed here as a marker to index a type of orientation to previous talk, which allows initiating a new, non-aligned and non-connected turn in a nevertheless other-attentive manner.

\section{Conclusion}

The rationale behind the decision to choose two very frequent DMs for this study was to focus on the resources actually deployed by L2 learners. By providing a detailed description of the interactional work within " $y$ "- and "sí"-prefaced turns, the analysis has illuminated that the L2 learners in this dataset can indeed build coherence over turns with a high level of delicacy and that overtly signalling the fitting (or otherwise) of a new turn with the previous talk seems to be a very important interactional task for these learners.

Moreover, probably the most interesting finding is that the ubiquity of " $y$ " and "sí" in turn beginnings that launch new actions is also an index of the preference for DMs that display continuity and affiliation, even if what the turn actually initiates is a sequence that disengages (in topic or stance) from the previous turn. Continuity and other-attentiveness play a very important role in this corpus, which contrasts with the observation made for L1 conversations that "there may be a greater likelihood that persons will have to manage breaks in sequential continuity more frequently than sequential continuities across breaks" (Heritage and Sorjonen 2018, 17).

Finally, I would like to make a note about pedagogical issues, which is necessarily brief due to space reasons. The fact that " $y$ " and "sí" are very frequent DMs does not imply that a pedagogical intervention will be superfluous, as not every contextual use of "y" and "sí" appears at every proficiency level and they are not produced by every speaker. "Y"-prefaced topic proffers seem to be quite an "accessible" resource, whereas the cases of, for example, "y"-prefaced topic continuations were restricted to a couple of participants. In this sense, and although the present conclusions are obviously limited to the analysed corpus, it can be envisaged that L2 learners in general would benefit from an approach that by drawing on insights from CA, raises students' awareness of conversational 
phenomena, as has already been suggested elsewhere (Barraja-Rohan 2011; Huth and Taleghani-Nikazm 2006; García García 2014). Such a pedagogical endeavour should consider the use of students' own recordings of classroom speaking (or much better, talking) activities other than role playing or simulations that promote personal exchange to thus generate the interactional space to establish not only connections between turns but also much more important, relationships between participants.

Acknowledgements Open Access funding provided by Projekt DEAL.

\section{Compliance with Ethical Standards}

Conflict of interest The corresponding author states that there is no conflict of interest.

Open Access This article is licensed under a Creative Commons Attribution 4.0 International License, which permits use, sharing, adaptation, distribution and reproduction in any medium or format, as long as you give appropriate credit to the original author(s) and the source, provide a link to the Creative Commons licence, and indicate if changes were made. The images or other third party material in this article are included in the article's Creative Commons licence, unless indicated otherwise in a credit line to the material. If material is not included in the article's Creative Commons licence and your intended use is not permitted by statutory regulation or exceeds the permitted use, you will need to obtain permission directly from the copyright holder. To view a copy of this licence, visit http://creativecommons.org/licen ses/by/4.0/.

\section{Appendix}

\section{Transcription conventions}

.hh Inbreath

? Rising intonation

! Animated talk

: Lengthened sound or syllable

- Abrupt ending or cutoff

${ }^{\circ}$ no sé ${ }^{\circ}$ Stretch of talk that is quieter than the surrounding talk

((clears throat)) Nonverbal action

(.) Short pause of less than $0.2 \mathrm{~s}$

(.5) Pause of $0.2-05 \mathrm{~s}$

(1.) Pause of approximately $1 \mathrm{~s}$

[Start of overlapping talk

() Uncertain transcription

$+\ldots+$ Phonetic transcription of a mispronounced word

\section{References}

Barraja-Rohan, A. M. (2011). Using conversation analysis in the second language classroom to teach interactional competence. Language Teaching Research, 15(4), 479-507. 
Bolden, G. B. (2006). Little words that matter: Discourse markers "So" and "Oh" and the doing of other-attentiveness in social interaction. Journal of Communication, 56(4), 661-688.

Buysse, L. (2012). So as a multifunctional discourse marker in native and learner speech. Journal of Pragmatics, 44, 1764-1782.

Campillos Llanos, L., \& González Gómez, P. (2014). Oral production of discourse markers by intermediate learners of Spanish: A corpus perspective. In F. Romero Trillo (Ed.), Yearbook of corpus linguistics and pragmatics. New empirical and theoretical paradigms (pp. 239-259). Basel: Springer.

Canale, M., \& Swain, M. (1980). Theoretical bases of communicative approaches to second language teaching and testing. Applied Linguistics, 1(1), 1-47.

Celce-Murcia, M. (2007). Rethinking the role of communicative competence in language teaching. In E. Alcón Soler \& P. Safont Jordà (Eds.), Intercultural language use and language learning (pp. 41-57). Dordrecht: Springer.

Cestero Mancera, A. M. (2000a). El intercambio de turnos de habla en la conversación. Análisis sociolingüístico. Alcalá de Henares: Servicio de Publicaciones de la Universidad de Alcalá.

Cestero Mancera, A. M. (2000b). Los turnos de apoyo conversacionales. Cádiz: Servicio de Publicaciones de la Universidad de Cádiz.

Council of Europe. (2001). Common European framework of reference for languages: Learning, teaching, assessment. Cambridge: Cambridge University Press.

Diskin, C. (2017). The use of the discourse-pragmatic marker 'like' by native and non-native speakers of English in Ireland. Journal of Pragmatics, 120, 144-157.

Dumitrescu, D. (2008). Usos discursivos del adverbio «sí» en el español mexicano. In A. Cunita, C. Lupu, \& L. Tasmowski (Eds.), Studii de lingüistica si filologie romanica: hommages offerts à Sanda Reinheimer Ripeanu (pp. 233-244). Bucuresti: Editura Universitatii din Bucuresti.

Fischer, K. (2000). Discourse particles, turn-taking, and the semantics-pragmatics interface. Revue de Sémantique et Pragmatique, 8, 111-137.

Flores-Ferrán, N., \& Lovejoy, K. (2015). An examination of mitigating devices in the argument interactions of L2 Spanish learners. Journal of Pragmatics, 76, 67-86.

García García, M. (2014). La competencia conversacional en español como lengua extranjera: Análisis y propuesta didáctica. Universidad de Alcalá: Servicio de Publicaciones.

García García, M. (2015). Tareas de conversación y patrones de interacción entre aprendientes de ELE, $e$-AESLA, 1. https://cvc.cervantes.es/lengua/eaesla/pdf/01/07.pdf.

Gardner, R. (2001). When listeners talk: Response tokens and listener stance. Amsterdam: John Benjamins Publishing.

Garfinkel, H. (1967). Studies in ethnomethodology. Englewood Cliffs, NJ: Prentice-Hall Inc.

Hall, J. K., Hellermann, J., \& Pekarek Doehler, S. (Eds.). (2011). L2 interactional competence and development. Bristol: Multilingual Matters.

Heritage, J. (2013). Turn-initial position and some of its occupants. Journal of Pragmatics, 57, 331-337.

Heritage, J., \& Sorjonen, M.-L. (1994). Constituting and maintaining activities across sequences: Andprefacing as a feature of question design. Language in Society, 23, 1-29.

Heritage, J., \& Sorjonen, M.-L. (2018). Introduction: Analyzing turn-initial particles. In J. Heritage \& M.-L. Sorjonen (Eds.), Between turn and sequence: Turn-initial particles across languages (pp. 1-22). Amsterdam: John Benjamins Publishing.

House, J. (2002). Developing pragmatic competence in English as lingua franca. In K. Knapp \& C. Meierkord (Eds.), Lingua franca communication (pp. 245-267). Frankfurt: Peter Lang.

House, J. (2013). Developing pragmatic competence in English as a lingua franca: Using discourse markers to express (inter)subjectivity and connectivity. Journal of Pragmatics, 59, 57-67.

Huth, T., \& Taleghani-Nikazm, C. (2006). How can insights from CA be directly applied to teaching L2 pragmatics? Language Teaching Research, 10, 53-79.

Hymes, D. H. (1972). On communicative competence. In J. B. Pride \& J. Holmes (Eds.), Sociolinguistics. Selected readings (pp. 269-293). London: Penguin Books.

Jefferson, G. (1984). On stepwise transition from talk about a trouble to inappropriately next-positioned matters. In A. J. Maxwell \& J. Heritage (Eds.), Structures of social action. Studies in conversation analysis (pp. 191-222). Cambridge: Cambridge University Press.

Jefferson, G. (1993). Caveat speaker: Preliminary notes on recipient topic-shift implicature. Research on Language and Social Interaction, 26(1), 1-30. 
Kim, Y. (2009). Korean discourse markers in L2 Korean speakers' conversation: An acquisitional perspective. In H. T. Nguyen \& G. Kasper (Eds.), Talk-in-interaction: Multilingual perspectives (pp. 317-350). Honolulu: University of Hawai'I.

Kim, H. R. S., \& Kuroshima, S. (2013). Turn beginnings in interaction: An introduction. Journal of Pragmatics, 57, 267-273.

Levinson, S. C. (2013). Action formation and ascription. In J. Sidnell \& T. Stivers (Eds.), Handbook of conversation analysis (pp. 103-130). Malden, MA: Wiley-Blackwell.

Martín Zorraquino, M. A., \& Portolés Lázaro, J. (1999). Los marcadores del discurso. In I. Bosque \& V. Demonte (Eds.), Gramática Descriptiva de la Lengua Española (pp. 4051-4213). Madrid: Espasa.

Maynard, D. W. (1980). Placement of topic changes in conversation. Semiotica, 30(3/4), 263-290.

Mortensen, K., \& Wagner, J. (2012). Conversation analysis: Overview. In C. A. Chapelle (Ed.), The encyclopedia of applied linguistics (pp. 1061-1068). Oxford, UK: Blackwell Publishing Ltd.

Pekarek Doehler, S. (2018). Elaborations on L2 interactional competence: The development of L2 grammar-for-interaction. Classroom Discourse, 9(1), 3-24.

Pekarek Doehler, S., \& Berger, E. (2018). L2 interactional competence as increased ability for contextsensitive conduct. A longitudinal study of story-openings. Applied Linguistics, 39(4), 555-578.

Polat, B. (2011). Investigating acquisition of discourse markers through a developmental learner corpus. Journal of Pragmatics, 43, 3745-3756.

Pons Bordería, S. (2000). Los conectores. In A. Briz \& Grupo Val.Es.Co (Eds.), ¿Cómo se comenta un texto coloquial? (pp. 193-220). Barcelona: Ariel.

Psathas, G. (1990). Introduction. Methodological issues and recent developments in the study of naturally occurring interaction. In G. Psathas (Ed.), Interaction competence (pp. 1-29). Washington, DC: University Press of America.

Richards, K. (2005). Introduction. In K. Richards \& P. Seedhouse (Eds.), Applying conversation analysis (pp. 1-18). Basingstoke: Palgrave Macmillan.

Sacks, H. (1992). Lectures on conversation. Oxford: Blackwell Publishers.

Sacks, H., Schegloff, E. A., \& Jefferson, G. (1974). A simplest systematics for the organization of turntaking for conversation. Language, 50, 696-735.

Schegloff, E. A. (1993). Reflections on quantification in the study of conversation. Research on Language and Social Interaction, 26(1), 99-128.

Schegloff, E. A. (2007). Sequence organization in interaction. Cambridge: Cambridge University Press.

Steensig, J. (2012). Conversation analysis and affiliation and alignment. In C. A. Chapelle (Ed.), The encyclopedia of applied linguistics. Oxford: Blackwell Publishing Ltd.

Wagner, J., \& Gardner, R. (2004). Introduction. In R. Gardner \& J. Wagner (Eds.), Second language conversations (pp. 1-17). London: Continuum.

Waring, H. Z. (2003). "Also" as a discourse marker: Its use in disjunctive and disaffiliative environments. Discourse Studies, 5(3), 415-436.

Wong, J. (2000). The token "yeah" in nonnative speaker English conversation. Research on Language and Social Interaction, 33(1), 39-67.

Wong, J., \& Waring, H. Z. (2010). Conversation analysis and second language pedagogy. New York: Routledge.

Wooffitt, R. (2005). Conversation analysis and discourse analysis: A comparative and critical introduction. London: Sage.

Publisher's Note Springer Nature remains neutral with regard to jurisdictional claims in published maps and institutional affiliations. 